\title{
Perancangan Sistem Daur Ulang Pasir Pada Industri Pengecoran Logam Skala Kecil Untuk Peningkatan Efisiensi Biaya Dan Pengurangan Limbah
}

\author{
Darma Firmansyah Undayat ${ }^{1}$, Cecep Ruskandi², M. Nur Hidajatullah ${ }^{3}$ \\ 1,2,3 Politeknik Manufaktur Bandung \\ 1,2,3 Jl. Kanayakan No. 21 Dago, Bandung 40135 \\ E-mail : darmafirmansyah@yahoo.com ${ }^{1}$
}

\begin{abstract}
Abstrak
Pengecoran logam merupakan suatu bagian dari proses manufaktur untuk menghasilkan produk yang pada umumnya memiliki bentuk yang rumit atau bahan yang tidak dapat diproses dengan pemesinan biasa. Tingkat kerumitan produk dapat dicapai dengan penggunaan cetakan yang terbuat dari pasir dan penggunaan inti yang juga terbuat dari pasir. Proses daur ulang pasir dapat dilakukan dengan metode daur ulang secara mekanis, thermal dan kimiawi. Sistem pasir yang telah digunakan menghasilkan limbah berupa pasir bekas, debu dan kontaminan lain. Limbah ini dapat digunakan untuk beberapa keperluan antara lain: digunakan kembali sebagai pasir pengecoran logam, pembuatan jalan, bahan brick dll. Selama ini daur ulang dilakukan pada pengecoran logam dengan skala besar. Untuk skala menengah dan kecil hal ini tidak dilakukan. Pasir bekas diperlakukan sebagai limbah yang dibuang dan tidak termanfaatkan. Pembuatan sistem daur ulang pasir untuk pengecoran logam memungkinkan penggunaan kembali pasir limbah untuk pasir cetak dengan sifat teknis pasir yang memenuhi kualitas yang diinginkan. Hal ini juga akan dapat mengurangi limbah yang dibuang oleh pengecoran logam. Penelitian dimulai dengan studi literatur untuk mengetahui karakteristik pasir bekas. Selanjutnya dilakukan perencanaan proses daur ulang pasir bekas tersebut, yang kemudian dilanjutkan dengan percobaan daur ulang pasir secara manual. Terhadap pasir hasil daur ulang tersebut kemudian dilakukan pengujian untuk mengetahui sifatnya. Hasil percobaan daur ulang dan hasil pengujian kemudian dianalisis untuk dijadikan salah satu dasar dalam perancangan dan pembuatan mesin daur ulang pasir untuk pengecoran logam skala kecil. Jenis pasir yang akan didaur ulang adalah pasir proses $\mathrm{CO}_{2}$ dengan bahan dasar pasir kuarsa. Berdasarkan penelitian yang telah dilakukan diperoleh kesimpulan sebagai berikut: teknologi daur ulang pasir proses $\mathrm{CO}_{2}$ yang dihasilkan adalah dalam bentuk sistem daur ulang dan analisis/ kajian mengenai kualitas daur ulang; desain purwarupa mesin daur ulang pasir proses $\mathrm{CO}_{2}$ yang dihasilkan adalah desain mesin jaw crusher dan desain mesin hammer mill.
\end{abstract}

Kata Kunci: pengecoran logam, pasir proses $\mathrm{CO}_{2}$, limbah, daur ulang

\begin{abstract}
Metal casting is a part of the manufacturing process to produce products that generally have intricate shapes or materials that can not be processed by ordinary machining. The complexity of the product can be achieved with the use of sand molds and the use of cores that are also made of sand. The process of recycling sand can be done by mechanical, thermal and chemical recycling methods. The sand system that has been used to produce waste in the form of waste sand, dust and other contaminants. This waste can be used for several purposes, among others: reused as metal casting sand, road construction, brick material etc. So far, recycling has been done on large scale metal casting. For medium and small scale this is not done. Used sand is treated as waste that is discarded and not utilized. The manufacture of a sand recycling system for metal casting allows the reuse of waste sand for print sand with the technical properties of sand that meet the desired quality. It will also be able to reduce waste disposed by metal casting. The study began with a literature study to find out the characteristics of used sand. Next is to plan the recycling process of the former sand, which then continued with manual sand recycling experiment. Against the recycled sand is then tested to determine its properties. The results of recycling experiments and test results are then analyzed to serve as a basis for designing and manufacturing sand recycling machines for small scale metal casting. The type of sand to be recycled is the $\mathrm{CO}_{2}$ process sand with a base of quartz sand. Based on the research that has been done, the following conclusions are obtained: $\mathrm{CO}_{2}$ process recycling sand technology produced is in the form of recycling system and analysis / study on the quality of recycling; design prototype sand recycling machine $\mathrm{CO}_{2}$ process produced is a design engine jaw crusher and hammer mill machine design.
\end{abstract}

Keywords: metal casting, $\mathrm{CO}_{2}$ process sand, waste, recycling 


\section{PENDAHULUAN}

Pengecoran logam merupakan suatu bagian dari proses manufaktur untuk menghasilkan produk yang pada umumnya memiliki bentuk yang rumit atau bahan yang tidak dapat diproses dengan pemesinan biasa. Tingkat kerumitan produk dapat dicapai dengan penggunaan cetakan yang terbuat dari pasir dan penggunaan inti yang juga terbuat dari pasir. Pasir digunakan dalam pengecoran karena sifatnya yang dapat dibentuk dengan mudah, memiliki ketahanan terhadap suhu tinggi dan reaksi terhadap bahan logam yang relatif kecil. Dengan teknik pemadatan dan pengerasan yang sesuai, pasir ini dapat dibentuk hingga memiliki kekuatan mekanis yang memadai untuk menahan tekanan metalostatis logam. Untuk mendapatkan sifat tersebut maka pasir akan dicampur dengan komponen lainnya dan diolah dengan sistem yang bervariasi menurut jenis komponen yang digunakan. Komponen utama sistem pasir terdiri dari bahan baku pasir, perekat, pelarut, katalis dan bahan tambah lain untuk mendapatkan sifat tertentu pasir, misalnya sifat mampu bongkar.

Pasir bekas pada industri pengecoran berskala besar digunakan kembali sebagai pasir daur ulang yang tentu saja berpengaruh terhadap penurunan kualitas pasir. Untuk itu dilakukan penambahan pasir baru dan komponen lainnya untuk mengkompensasi penurunan kualitas. Proses daur ulang pasir dapat dilakukan dengan metode daur ulang secara mekanis, thermal dan kimiawi. Sistem pasir yang telah digunakan menghasilkan limbah berupa pasir bekas, debu dan kontaminan lain. Limbah ini dapat digunakan untuk beberapa keperluan antara lain: digunakan kembali sebagai pasir pengecoran logam, pembuatan jalan, bahan brick dll.

Selama ini daur ulang dilakukan pada pengecoran logam dengan skala besar. Untuk skala menengah dan kecil hal ini tidak dilakukan. Pasir bekas diperlakukan sebagai limbah yang dibuang dan tidak termanfaatkan. Pembuatan sistem daur ulang pasir untuk pengecoran logam memungkinkan penggunaan kembali pasir limbah untuk pasir cetak dengan sifat teknis pasir yang memenuhi kualitas yang diinginkan. Hal ini juga akan dapat mengurangi limbah yang dibuang oleh pengecoran logam.

\section{METODE}

Penelitian ini bertujuan untuk menghasilkan teknologi daur ulang pasir pengecoran logam skala kecil dan rancangan purwarupa mesin daur ulang. Jenis pasir yang akan di daur ulang akan dikhususkan pada pasir proses $\mathrm{CO}_{2}$ dengan bahan dasar pasir kuarsa.

Berikut ini adalah diagram alir langkah-langkah pelaksanaan penelitian yang akan dilakukan (Gambar 1). detail.

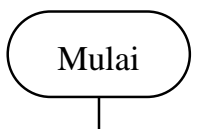

Karakteristik pasir proses $\mathrm{CO}_{2}$ bekas
Perencanaan daur ulang pasir proses $\mathrm{CO}_{2}$

Proses daur ulang pasir proses $\mathrm{CO}_{2}$ secara manual

Analisis kualitas pasir hasil percobaan

Perancangan mesin daur ulang pasir proses $\mathrm{CO}_{2}$ Selesai

Gambar 1. Diagram alir penelitian

Karakteristik pasir proses $\mathrm{CO}_{2}$ bekas, didapatkan dari hasil studi literatur yang meliputi komposisi, penggunaan dan sifat pasir bekas.

Perencanaan daur ulang pasir proses $\mathrm{CO}_{2}$, menentukan metode daur ulang yang dapat diterapkan dan komponen proses yang harus dipenuhi. Cetakan pasir proses $\mathrm{CO}_{2}$ setelah dibongkar biasanya berupa bongkahan dengan ukuran antara $6 \mathrm{~cm}$ sampai $26 \mathrm{~cm}$ seperti terlihat pada Gambar 2. Untuk mendaur ulang pasir tersebut diperlukan beberapa tahapan proses tergantung tipe sistem daur ulang yang dipilih. Salah satu tujuan dari penelitian ini adalah pasir proses $\mathrm{CO}_{2}$ bekas yang berupa bongkahan dapat diolah agar berbentuk butiran kembali sehingga bisa diolah kembali menjadi pasir $\mathrm{CO}_{2}$ baru yang siap digunakan. Untuk dapat mencapai tujuan tersebut, sistem daur ulang pasir yang tepat untuk dipilih adalah tipe dry reclamation, yaitu memanfaatkan gesekan secara mekanik atau prinsip gesekan untuk menghilangkan lapisan bahan pengikatnya.
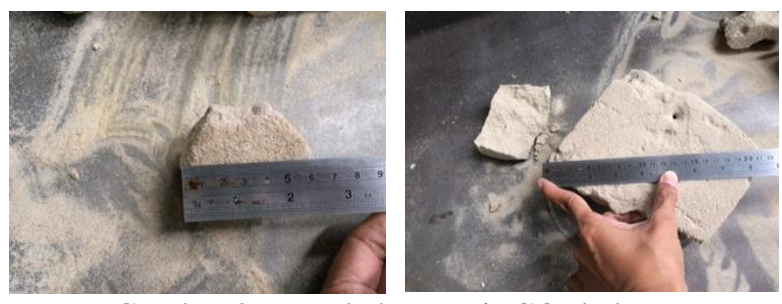

Gambar 2. Bongkahan pasir $\mathrm{CO}_{2}$ bekas

Proses daur ulang pasir proses $\mathrm{CO}_{2}$ secara manual, merupakan rangkaian percobaan untuk mendapatkan bahan baku pasir dari pasir proses $\mathrm{CO}_{2}$ bekas pengecoran logam. Proses daur ulang dilakukan sesuai dengan yang telah direncanakan pada tahap sebelumnya, yaitu proses pemecahan bongkahan pasir dengan jaw crusher diwakili dengan proses pemukulan bongkahan dengan palu/ penumbuk pasir, sedangkan proses penghalusan butiran 
dengan hammer mill diwakili dengan proses penyaringan menggunakan ayakan dengan diameter lubang 1,4 mm.
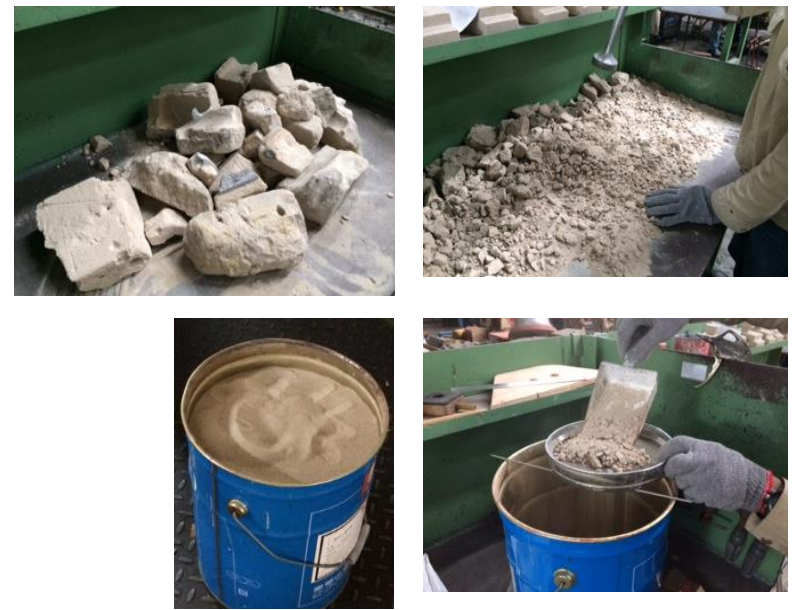

Gambar 3. Proses daur ulang pasir $\mathrm{CO}_{2}$ bekas secara manual

Analisis kualitas pasir hasil percobaan daur ulang, mencakup analisis butiran pasir, permukaan pasir, sifat thermal dan sifat fisik pasir serta pengujian sistem untuk menguji sifat mekanik pasir. Pasir $\mathrm{CO}_{2}$ bekas yang telah mengalami proses penghancuran dan penyaringan ( $d r y$ reclamation) selanjutnya diuji kualitasnya di laboratorium untuk mengetahui karakteristiknya. Karakteristik yang perlu diketahui dari pasir $\mathrm{CO}_{2}$ bekas hasil proses dry reclamation terdiri atas : Bagian hilang terbakar (Loss on ignition (LOI)), Kadar debu, titik sinter dan distribusi ukuran pasir. Proses pengujian seperti ditunjukkan pada gambar 4 dan hasil pengujian ditunjukan pada Tabel 1 sebagai berikut.

Tabel 1. Hasil pengujian pasir

\begin{tabular}{|c|c|c|}
\hline Sifat & $\begin{array}{c}\text { Pasir daur } \\
\text { ulang }\end{array}$ & Pasir baru \\
\hline LOI & $0,21 \%$ & $0,42 \%$ \\
\hline Kadar debu & $4,17 \%$ & $1,00 \%$ \\
\hline Titik sinter & $>1200^{\circ} \mathrm{C}$ & $>1200{ }^{\circ} \mathrm{C}$ \\
\hline $\begin{array}{c}\text { Luas permukaan } \\
\text { butiran }\end{array}$ & $136 \mathrm{~cm}^{2} / \mathrm{gr}$ & $129 \mathrm{~cm}^{2} / \mathrm{gr}$ \\
\hline $\begin{array}{c}\text { Besar butiran } \\
\text { rata-rata }\end{array}$ & $0,21 \mathrm{~mm}$ & $0,22 \mathrm{~mm}$ \\
\hline AFS Number & 77 & 73 \\
\hline
\end{tabular}
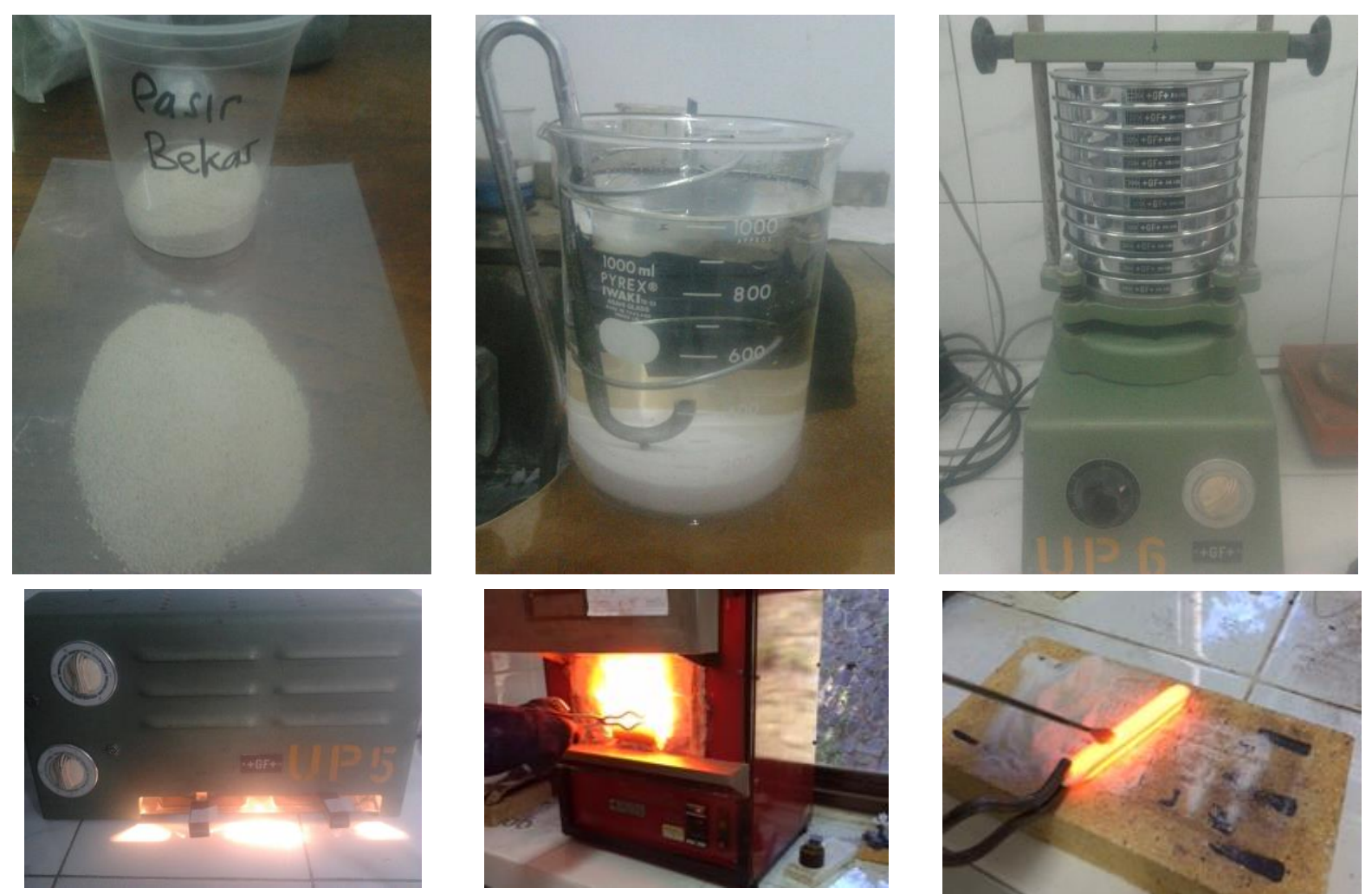

Gambar 4. Proses pengujian pasir $\mathrm{CO}_{2}$ hasil dry reclamation

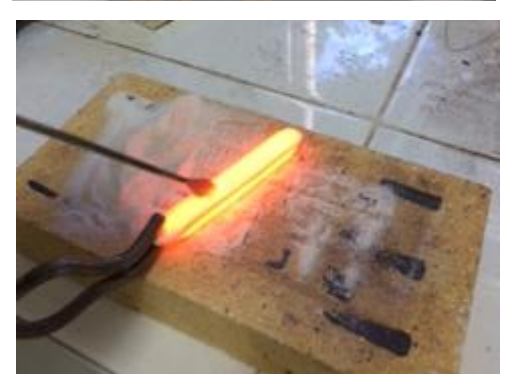

\section{Karakteristik pasir proses $\mathrm{CO}_{2}$ bekas}

Perancangan mesin daur ulang pasir proses $\mathrm{CO}_{2}$, diperuntukkan bagi industri pengecoran logam skala kecil. Mesin mencakup crusher dan refiner.

\section{HASIL DAN PEMBAHASAN}

Menurut C. Kim Ng, P.K. Yeo \& C.M. Fam (2014) pasir proses $\mathrm{CO}_{2}$ hasil daur ulang memiliki karakteristik sebagai berikut:

1. Distribusi ukuran pasir dapat dilihat pada Gambar 5, yang menunjukan sebagian besar berada di grain 
fineness number (GFN) 50 mesh yang ekivalen dengan $24,5 \%$ dan $35,5 \%$ dari berat total pasir. Serta hanya ada $1 \%$ pasir dengan GFN 16 mesh dan 0,5\% debu yang lebih halus dari GFN 100 mesh. Distribusi ukuran pasir akan berpengaruh terhadap kualitas coran. Ukuran butir yang kasar dapat mengakibatkan penetrasi logam ke dalam cetakan dan akan mengakibatkan permukaan coran yang jelek. Ukuran butir yang halus akan menghasikan permukaan coran yang lebih baik, tetapi membutuhkan bahan pengikat yang lebih banyak dan memiliki kemampuan alir gas yang rendah yang dapat mengakibatkan cacat gas pada coran. Sehingga ukuran pasir seharusnya terdistribusi diantara GFN 20 mesh hingga GFN 100 mesh untuk pasir baru.

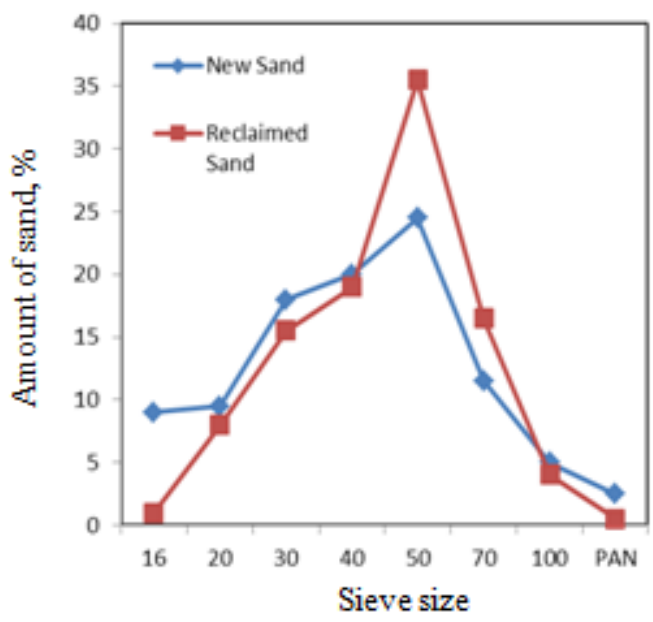

Gambar 5. Distribusi ukuran pasir baru dan pasir daur ulang

2. Bentuk partikel pasir dapat dilihat pada Gambar 6, lingkaran menunjukan terdapat banyak pasir yang berbentuk menyudut pada pasir baru, dibandingkan dengan pasir daur ulang yang berbentuk bulat. Hal ini diakibatkan oleh gesekan antar pasir dan tumbukan pasir terhadap dinding pada saat proses daur ulang pasir yang mengakibatkan bagian ujung menyudut menjadi bulat. Butiran yang bulat akan memberikan kemampuan alir yang baik dan kepadatan yang tinggi pada penambahan bahan pengikat yang rendah jika dibandingkan dengan butiran yang bersudut (Brown 1999). Sehingga pasir daur ulang dapat mengurangi penggunaan jumlah bahan pengikat dalam proses pembuatan cetakan, sehingga dapat meningkatkan collapsibility cetakan pasir.

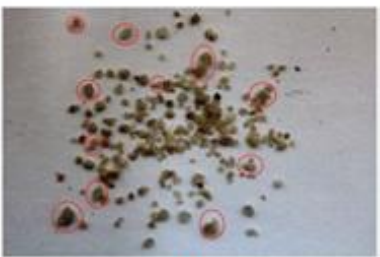

(a)

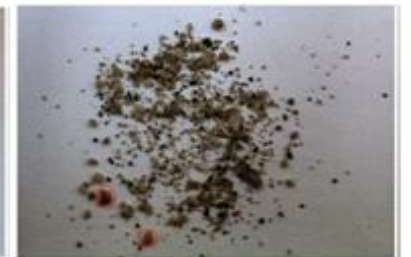

(b)
Gambar 6. Bentuk partikel (a) pasir baru, (b) pasir daur ulang
3. Kekuatan tekan, tarik dan geser dari pasir daur ulang yang dibuat dengan beberapa variasi jumlah bahan pengikat yang ditambahkan dapat dilihat pada Gambar 7 sebagai berikut.

(a)

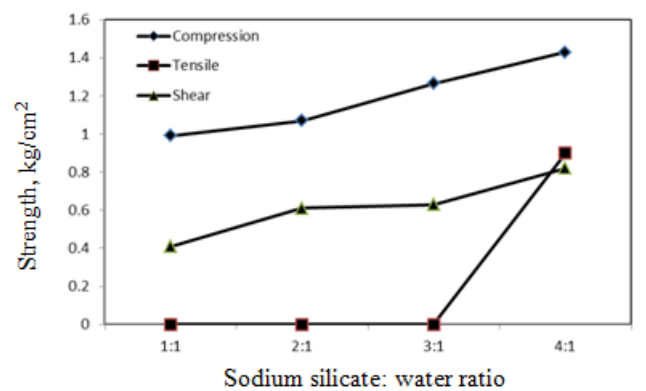

(b)

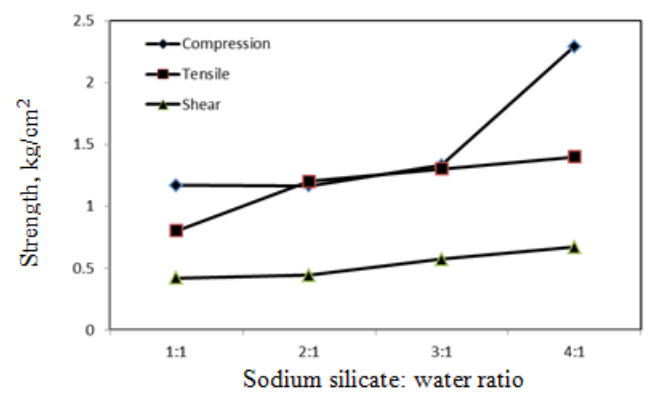

(c)

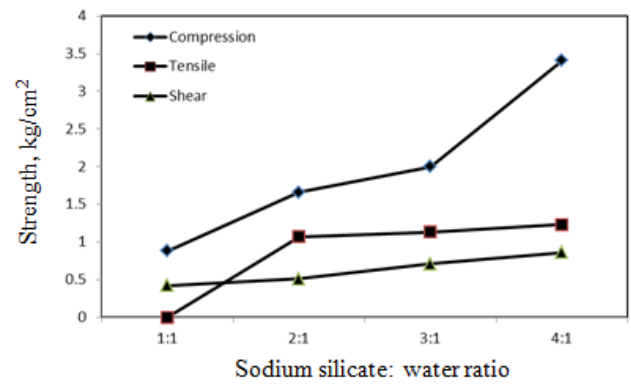

Gambar 7. Kuat tekan tarik dan geser untuk pasir yang dibuat dengan (a) $4 \%$ bahan pengikat, (b) 5 $\%$ bahan pengikat (c) $6 \%$ bahan pengikat (sodium silicate dan air).

4. Collapsibility cetakan pasir yang dibuat dengan beberapa variasi jumlah bahan pengikat dapat dilihat pada Gambar 8.

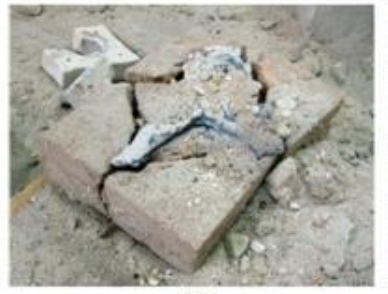

(a)

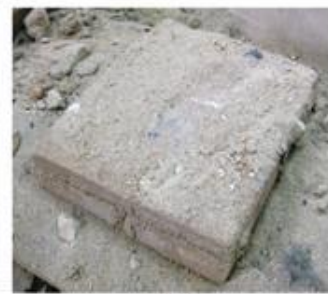

(b)

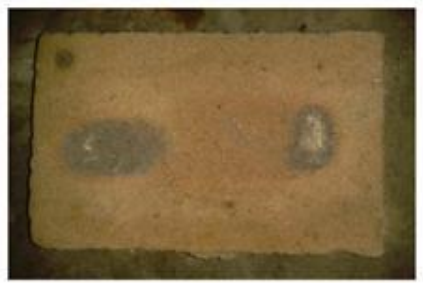

(c) 
Gambar 8. Kondisi cetakan pasir yang dibuat dengan (a) $4 \%$, (b) $5 \%$, (c) $6 \%$ bahan pengikat (4:1 rasio sodium silicate terhadap air) setelah penuangan besi cor

\section{Perencanaan daur ulang pasir proses $\mathrm{CO}_{2}$}

Sistem daur ulang pasir secara umum ada tiga tipe, yaitu: dry reclamation; wet reclamation; dan thermal reclamation (J.M. Svoboda, 1990). Masing-masing tipe sistem daur ulang memiliki kelebihan dan kekurangan. Permasalahan yang dihadapi industri pengecoran logam skala kecil saat ini adalah pasir proses $\mathrm{CO}_{2}$ yang telah digunakan biasanya langsung dibuang sehingga biaya untuk pebuatan kembali pasir tersebut cukup tinggi, karena bahan baku yang digunakannya adalah pasir baru seluruhnya. Agar pasir proses $\mathrm{CO}_{2}$ bekas dapat digunakan kembali, perlu dilakukan proses daur ulang terhadap pasir bekas tersebut.

Tahapan proses yang direncanakan untuk mendaur ulang pasir proses $\mathrm{CO}_{2}$ bekas dengan sistem tipe $d r y$ reclamation meliputi: proses penghancuran bongkahan pasir dan proses penghalusan butiran pasir. Proses penghancuran bongkahan pasir dapat dilakukan dengan menggunakan mesin jaw crusher, sedangkan proses penghalusan butiran pasir dilakukan dengan mesin hammer mill.

Untuk keperluan proses daur ulang secara manual, proses pemecahan bongkahan pasir dengan jaw crusher diwakili dengan proses pemukulan bongkahan dengan palu/ penumbuk pasir, sedangkan proses penghalusan butiran dengan hammer mill diwakili dengan proses penyaringan menggunakan ayakan dengan diameter lubang $1,4 \mathrm{~mm}$.

\section{Pengujian dan analisis kualitas pasir hasil daur ulang}

Berdasarkan hasil pengujian seperti yang tunjukan pada Tabel 1, pasir hasil percobaan daur ulang secara manual memiliki sifat yang lebih rendah dari pasir baru. Hal tersebut normal karena pasir setelah diolah dengan penambahan bahan pengikat dan bahan tambah yang kemudian dibuat cetakan dan menerima beban panas ketika dicor, akan mengalami penurunan sifat-sifatnya.

\section{Mekanisme perancangan mesin daur ulang pasir proses $\mathrm{CO}_{2}$}

I. Identifikasi jenis dan fungsi mesin daur ulang pasir $\mathrm{CO}_{2}$

Mesin daur ulang pasir proses $\mathrm{CO}_{2}$ direncanakan terdiri dari dua jenis mesin, sesuai dengan tahapan proses daur ulang yang akan dilakukan. Kedua jenis mesin tersebut adalah jaw crusher dan hammer mill.

\section{Perancangan mesin jaw crusher}

Perancangan mesin jaw crusher dimulai dari analisis objek mesin, yaitu pasir proses $\mathrm{CO}_{2}$ bekas. Pasir proses $\mathrm{CO}_{2}$ bekas merupakan hasil pembongkaran cetakan yang berasal dari cetakan atau inti. Biasanya masih berupa bongkahan dengan ukuran antara $6 \mathrm{~cm}$ sampai $26 \mathrm{~cm}$ seperti terlihat pada Gambar 2. Pasir proses $\mathrm{CO}_{2}$ terdiri dari pasir kwarsa sebagai bahan dasar, air kaca yang sudah mengkristal sebagai bahan pengikat dan lapisan tipis gula tetes sebagai bahan tambah. Pasir tersebut memiliki sifat yang abrasif.

Untuk mendaur ulang pasir proses $\mathrm{CO}_{2}$ bekas tersebut di atas, harus dilakukan terlebih dahulu proses penghancuran bongkahan pasir. Rencananya akan digunakan metoda jaw crusher, yaitu bongkahan akan dipukul oleh dua pelat hingga hancur. Prinsip kerja mesin jaw crusher ini adalah bongkahan pasir akan masuk ke dalam celah yang dibentuk oleh dua buah pelat pemukul yang berbentuk tirus, yaitu lebar pada bagian atas, dan mengecil pada bagian bawah. Kemudian bongkahan tersebut akan dipukul oleh pelat dengan mekanisme salah satu pelat diam, dan pelat yang lainnya bergerak memukul. Lebar celah bagian bawah bisa disesuaikan dengan besar pecahan bongkahan yang ingin dihasilkan. Secara umum mesin jaw crusher terdiri dari beberapa bagian seperti yang terlihat pada Gambar 9 sebagai berikut.

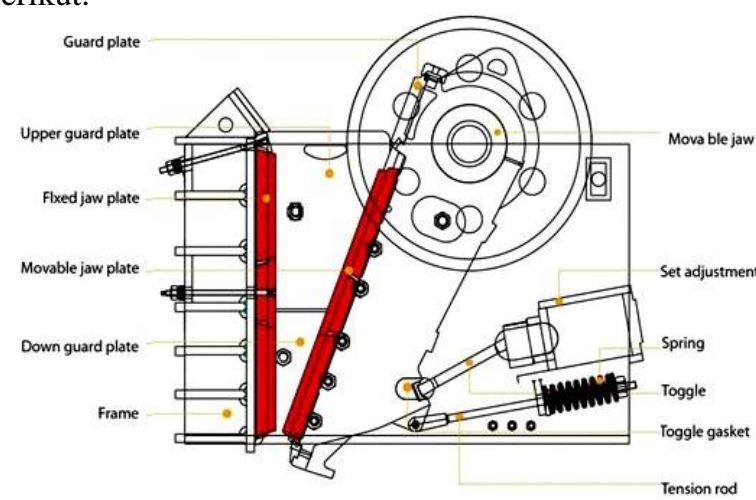

Gambar 9. Bagian-bagian mesin jaw crusher

Perancangan mesin jaw crusher akan dilakukan mengikuti konstruksi mesin seperti yang ditunjukan pada Gambar 9 tersebut diatas. Hal baru yang akan dilakukan dalam penelitian ini adalah pemilihan material bagian fixed jaw plate dan moveable jaw platenya. Pemilihan materialnya akan disesuaikan dengan karakteristik objek dari mesin tersebut, yaitu pasir $\mathrm{CO}_{2}$ bekas yang abrasif.

\section{Perancangan mesin hammer mill}

Perancangan mesin hammer mill dimulai dari analisis objek mesin, yaitu pasir proses $\mathrm{CO}_{2}$ bekas yang telah diproses oleh mesin jaw crusher. Pasir proses $\mathrm{CO}_{2}$ bekas yang dihasilkan oleh mesin jaw crusher masih berupa gumpalan pasir yang kecil-kecil dan belum terurai menjadi butiran-butiran pasir. 


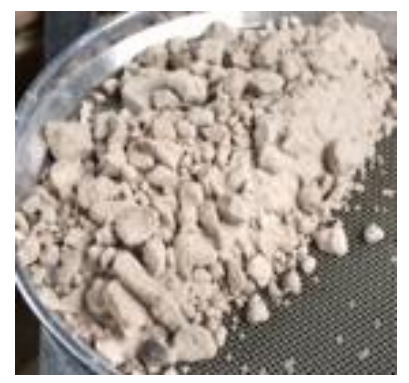

Gambar 10. Pasir proses $\mathrm{CO}_{2}$ yang dihasilkan oleh mesin jaw crusher

Agar gumpalan pasir tersebut diatas dapat terurai menjadi butiran-butiran pasir, direncanakan akan digunakan metode hammer mill untuk mengolahnya. Prinsip kerja mesin hammer mill adalah gumpalan pasir akan masuk ke dalam ruang dimana di dalamnya ada palu yang berputar. Gumpalan pasir akan dipukul oleh palu berputar kemudian menabrak dinding ruang, dan berulang seperti itu hingga gumpalan pasir terurai dan dapat masuk ke saringan yang ada pada bagian bawah mesin.

Secara umum mesin hammer mill terdiri dari beberapa bagian seperti yang terlihat pada Gambar 11 sebagai berikut.

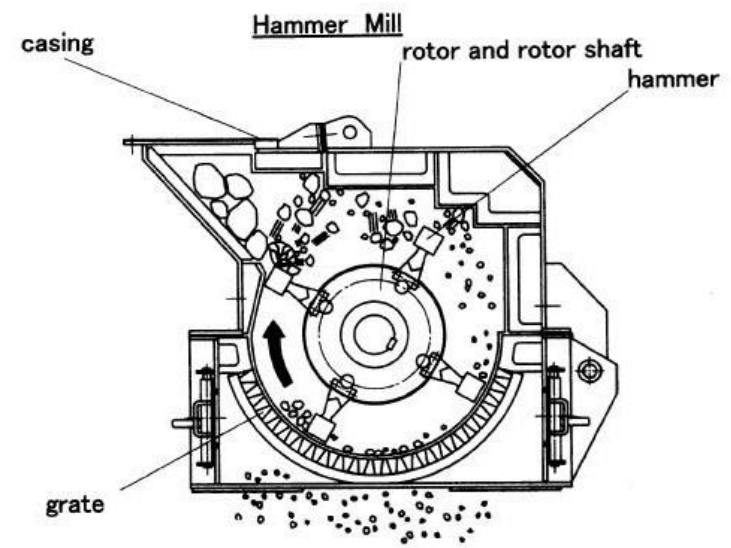

Gambar 11. Bagian-bagian mesin hammer mill Perancangan mesin hammer mill akan dilakukan mengikuti konstruksi mesin seperti yang ditunjukan pada Gambar 11 tersebut diatas. Hal baru yang akan dilakukan dalam penelitian ini adalah pemilihan material bagian hammernya. Pemilihan materialnya akan disesuaikan dengan karakteristik objek dari mesin tersebut, yaitu pasir $\mathrm{CO}_{2}$ bekas yang abrasif.

II. Analisis tuntutan/persyaratan teknis dan penentuan sifat bahan yang dibutuhkan.

Ketika menjalankan fungsinya sebagai penghancur dan pendaur ulang bongkahan pasir cetak yang telah terpakai, setiap $\mathrm{n}$ mesin yang kontak langsung dengan pasir cetak akan mengalami berbagai kondisi pembebanan sebagaimana ditunjukkan dalam tabel berikut :

Tabel 2. Kondisi Pembebanan

\section{\begin{tabular}{l|l} 
Elemen Mesin & Kondisi Pembebanan \\
\hline
\end{tabular}}

\begin{tabular}{|l|l|}
\hline Jaw Crusher & Abrasif (gesek) dan benturan \\
\hline Hammer Mill & Benturan \\
\hline
\end{tabular}

Objek yang dihadapi oleh Jaw Crusher adalah pasir $\mathrm{SiO}_{2}$ yang merupakan bahan keramik ditambah dengan bahan pengikat yang sudah menjadi kristal akibat reaksi dengan gas $\mathrm{CO}_{2}$. Bahan keramik secara umum memiliki kekerasan yang sangat tinggi dan apabila bergesekan dengan material lain akan bersifat mengabrasif lawan geseknya sehingga material akan mengalami keausan. Pasir $\mathrm{CO} 2$ bekas yang akan didaur ulang adalah pasir yang berbentuk bongkahan dengan ukuran berkisar antara 60 hingga $260 \mathrm{~mm}$. Sedangkan pasir Silika yang sudah didaur ulang diharapkan memiliki ukuran sekitar 0,25 hingga $0,35 \mathrm{~mm}$. Oleh karena itu untuk menghancurkan bongkahan tersebut mesin Jaw Crusher juga harus memiliki sifat tahan terhadap benturan karena mekanisme yang digunakan untuk menghancurkan bongkahan menjadi pasir halus adalah dengan cara benturan atau pemukulan. Rata-rata nilai kekerasan pasir silika $\mathrm{SiO} 2$ adalah 5 skala Mohs atau setara dengan 51 HRC.

Objek yang dihadapi oleh Hammer mill adalah bongkahan pasir hasil proses penghancuran oleh mesin Jaw Crusher hanya saja ukuran bongkahannya lebih kecil. Pada prosesnya bongkahan tersebut dihancurkan oleh Hammer Mill melalui proses pemukulan. Dengan demikian maka tuntutan utama dari sifat bahan yang tepat untuk Hammer Mill adalah material yang tangguh namun juga dapat ditingkatkan kekerasannya melalui proses perlakuan panas sehingga ketahanan abrasifnya akan menjadi lebih baik.

\section{Studi bahan dan aplikasinya}

Bahan teknik secara garis besar terdiri atas bahan logam, keramik dan polimer. Diantara bahan-bahan teknik tersebut logam dan keramik relatif memiliki kekerasan dan ketahanan abrasif yang lebih baik dibandingkan dengan polimer. Material keramik merupakan material yang secara umum paling keras namun material ini memiliki kekurangan yaitu dalam hal ketangguhannya yang rendah atau bersifat rapuh. Material logam memiliki kekuatan dan kekerasan yang lebih baik di bandingkan polimer, namun umumnya kekerasannya masih di bawah keramik. Akan tetapi ada satu hal penting yang dimiliki oleh logam yaitu bahwa nilai kekerasannya dapat diubah (ditingkatkan atau diturunkan ) melalui suatu metoda yang tepat tergantung pada jenis logamnya. Salah satu metoda yang sering dipergunakan untuk mengubah sifat logam adalah proses perlakuan panas.

Bahan logam pun secara garis besar dikelompokkan menjadi logam berbasis besi yang terdiri dari besi cor dan baja serta logam berbasis unsur non besi seperti logam Alumunium dan paduannya.

Berikut ini adalah beberapa jenis logam berbasis besi dan aplikasinya :

1. Besi cor, logam ini merupakan paduan logam besi dengan unsur karbon. Kandungan unsur karbon pada logam besi secara praktis berkisar antara $2-4 \%$. Besi 
cor ini terbagi menjadi berbagai jenis dengan masing masing aplikasinya sebagai berikut:

- Besi Cor kelabu, umumnya besi cor ini bersifat mudah untuk di proses pemesinan, memiliki sifat peredaman getaran yang baik serta mampu cor yang baik. Besi cor ini banyak dipakai untuk rumah mesin, rumah pompa, gear box, cylinder head dll.

- Besi cor ductile, banyak dipakai untuk produk yang dituntut harus bersifat ulet seperti poros engkol.

- Besi cor putih atau besi cor tahan abrasif. Umumnya besi cor ini memiliki sifat yang sangat keras tetapi bersifat rapuh. Besi cor ini dapat dibuat melalui proses pendingian yang sangat cepat dari kondisi cair menjadi padat atau melalui penambahan unsur paduan tertentu. Karena sifatnya yang keras tersebut maka besi cor ini dalam aplikasinya banyak dipakai untuk produkproduk yang dituntut harus tahan gesek atau tahan abrasif.

2. Baja Cor, logam ini juga merupakan paduan antara logam besi dengan unsur karbon akan tetapi dengan kadar karbon yang lebih rendah yaitu kurang dari $2 \%$.
Banyak sekali jenis baja yang tersedia, namun secara umum dapat dikelompokkan menjadi baja karbon dan baja paduan. Baja paduan secara umum memiliki keunggulan yang lebih baik dalam hal sifat-sifatnya dibandingkan baja karbon tergantung pada jenis dan unsur paduan yang dimiliki oleh baja tersebut. Seperti misalnya baja yang mengandung unsur paduan $\mathrm{Cr}$ dalam jumlah yang tinggi (>10\%) maka baja tersebut akan memiliki sifat tahan korosi. Jika baja tersebut juga mengandung unsur $\mathrm{Ni}$ yang tinggi maka akan selain memiliki sifat tahan korosi boleh jadi juga memiliki sifat tahan panas. Jika ke dalam baja tersebut dimasukkan unsur-unsur lain seperti Mo, V selain $\mathrm{Cr}$ dan Ni maka kekerasan baja pun akan meningkat sehingga dalam aplikasinya juga dapat dipergunakan pada produk yang dituntut harus tahan gesek dan kuat.

IV. Pemilihan bahan berdasarkan kriteria yang ditentukan

Fokus pada bahan yang dituntut harus memiliki kekerasan yang tinggi dan bersifat tahan gesek seperti halnya untuk jaw crusher, maka ada beberapa alternatif bahan yang bisa dipilih mengacu pada standar ASTM A532 yaitu :

Tabel 3. Standar ASTM A532

\begin{tabular}{|c|c|c|c|c|c|c|c|c|c|c|c|}
\hline Class & Type & Designation & Carbon & Manganese & Silicon & Nickel & Chromium & $\begin{array}{l}\text { Molyb- } \\
\text { denum }\end{array}$ & Copper & $\begin{array}{l}\text { Phos- } \\
\text { phorus }\end{array}$ & Sulfur \\
\hline I & A & $\mathrm{Ni}-\mathrm{Cr}-\mathrm{Hc}$ & $2.8-3.6$ & $2.0 \max$ & $0.8 \max$ & $3.3-5.0$ & $1.4-4.0$ & $1.0 \max$ & $\ldots$ & $0.3 \max$ & $0.15 \max$ \\
\hline I & B & $\mathrm{Ni}-\mathrm{Cr}-\mathrm{Lc}$ & $2.4-3.0$ & $2.0 \max$ & $0.8 \max$ & $3.3-5.0$ & $1.4-4.0$ & $1.0 \max$ & $\ldots$ & $0.3 \max$ & $0.15 \max$ \\
\hline i & C & $\mathrm{Ni}-\mathrm{Cr}-\mathrm{GB}$ & $2.5-3.7$ & $2.0 \max$ & $0.8 \max$ & $4.0 \max$ & $1.0-2.5$ & $1.0 \max$ & $\cdots$ & $0.3 \max$ & 0.15 max \\
\hline 1 & D & $\mathrm{Ni}-\mathrm{HiCr}$ & $2.5-3.6$ & $2.0 \max$ & $2.0 \max$ & $4.5-7.0$ & $7.0-11.0$ & $1.5 \max$ & & $0.10 \max$ & $0.15 \max$ \\
\hline II & A & $12 \% \mathrm{Cr}$ & $2.0-3.3$ & $2.0 \max$ & $1.5 \max$ & $2.5 \max$ & $11.0-14.0$ & $3.0 \max$ & $1.2 \max$ & 0.10 max & 0.06 max \\
\hline ॥ & B & $15 \%$ Cr-Mo & $2.0-3.3$ & $2.0 \max$ & $1.5 \max$ & $2.5 \max$ & $14.0-18.0$ & $3.0 \max$ & $1.2 \max$ & $0.10 \max$ & $0.06 \max$ \\
\hline$\|$ & D & $20 \%$ Cr-Mo & $2.0-3.3$ & $2.0 \max$ & $1.0-2.2$ & $2.5 \max$ & $18.0-23.0$ & $3.0 \max$ & $1.2 \max$ & $0.10 \max$ & $0.06 \max$ \\
\hline III & A & $25 \% \mathrm{Cr}$ & $2.0-3.3$ & $2.0 \max$ & $1.5 \max$ & $2.5 \max$ & $23.0-30.0$ & $3.0 \max$ & $1.2 \max$ & $0.10 \max$ & $0.06 \max$ \\
\hline
\end{tabular}

\begin{tabular}{|c|c|c|c|c|c|c|c|c|c|c|c|c|c|c|c|c|c|c|}
\hline \multirow{5}{*}{ Class } & \multirow{5}{*}{ Type } & \multirow{5}{*}{ Designation } & \multicolumn{15}{|c|}{ Hardness Value-HB } & \multirow{5}{*}{$\begin{array}{c}\text { Typical } \\
\text { Section } \\
\text { Thickness }\end{array}$} \\
\hline & & & \multicolumn{9}{|c|}{ Sand Cast, $\min ^{\wedge}$} & \multirow{2}{*}{\multicolumn{3}{|c|}{ Chill Cast, $\min ^{\theta}$}} & & & & \\
\hline & & & \multicolumn{3}{|c|}{$\begin{array}{c}\text { As Cast or As Cast and Stress } \\
\text { Relieved }\end{array}$} & \multicolumn{6}{|c|}{ Hardened or Hardened and Stress Relieved } & & & & \multicolumn{3}{|c|}{ Softened, max } & \\
\hline & & & & & & & Level 1 & & & Level 2 & & \multirow[b]{2}{*}{$\mathrm{HB}$} & \multirow[b]{2}{*}{ HRC } & \multirow[b]{2}{*}{ HV } & \multirow[b]{2}{*}{$\mathrm{HB}$} & \multirow[b]{2}{*}{ HRC } & \multirow[b]{2}{*}{ HV } & \\
\hline & & & HB & $\mathrm{HRC}$ & HV & $\mathrm{HB}$ & HRC & HV & $\mathrm{HB}$ & HRC & HV & & & & & & & \\
\hline 1 & A & $\mathrm{Ni}-\mathrm{Cr}$-HiC & 550 & 53 & 600 & 600 & 56 & 660 & 650 & 59 & 715 & 600 & 56 & 660 & & $\ldots$ & $\ldots$ & ... \\
\hline 1 & B & Ni-Cr-LoC & 550 & 53 & 600 & 600 & 56 & 660 & 650 & 59 & 715 & 600 & 56 & 660 & & $\ldots$ & r & $\ldots$ \\
\hline I & c & Ni-Cr-GB & 550 & 53 & 600 & 600 & 56 & 660 & 650 & 59 & 715 & 600 & 56 & 660 & 400 & 41 & 430 & \\
\hline 1 & D & $\mathrm{Ni-HiCr}$ & 500 & 50 & 540 & 600 & 56 & 660 & 650 & 59 & 715 & 550 & 53 & 600 & & & & $\ldots$ \\
\hline ॥ & A & $12 \% \mathrm{Cr}$ & 550 & 53 & 600 & 600 & 56 & 660 & 650 & 59 & 715 & 550 & 53 & 600 & 400 & 41 & 430 & \\
\hline II & B & $15 \%$ Cr-Mo & 450 & 46 & 485 & 600 & 56 & 660 & 650 & 59 & 715 & $\ldots$ & $\ldots$ & $\ldots$ & 400 & 41 & 430 & $\ldots$ \\
\hline ॥ & D & $20 \%$ Cr-Mo & 450 & 46 & 485 & 600 & 56 & 660 & 650 & 59 & 715 & & & & 400 & 41 & 430 & \\
\hline III & A & $25 \% \mathrm{Cr}$ & 450 & 46 & 485 & 600 & 56 & 660 & 650 & 59 & 715 & & & $\ldots$ & 400 & 41 & 430 & $\ldots$ \\
\hline
\end{tabular}

Kelas IA - IC secara umum dikenal juga dengan sebutan bahan NiHard I. Sedangkan kelas ID dikenal dengan sebutan NiHard4.

Data dari sumber lain menyatakan bahwa ketangguhan bahan Nihard 4 lebih baik dari pada bahan Nihard 1. Nilai $K_{\text {Ic }}$ Nihard 4 lebih dari $25 \mathrm{Mpa} \mathrm{m}$. Sedangkan nilai $\mathrm{K}_{\mathrm{Ic}}$ Nihard 1 maksimum $26 \mathrm{Mpa}$ m. Hal tersebut berarti meskipun nilai kekerasan Nihard 1lebih tinggi dari Nihard 4 namun dalam hal ketangguhan Nihard 4 lebih baik.
Kelas II memiliki kandungan unsur Mo yang lebih tinggi, namun berdasarkan tabel nilai kekerasan di atas, kekerasan besi cor kelas II ini lebih rendah dibandingkan kelas I. Sehingga dapat dianggap bahwa ketahanan gesek besi cor ini masih lebih rendah dibandingkan dengan besi cor kelas I. Demikian juga halnya dengan besi cor kelas III.

Berdasarkan pertimbangan tersebut, maka material yang dianggap tepat untuk produk Jaw Crusher adalah standar material ASTM A532 class ID atau NiHard 4. 
Sedangkan untuk Hammer Mill, memperhatikan fungsi dan mekanisme kerjanya maka bahan untuk produk ini harus memiliki ketangguhan yang lebih baik meskipun nilai kekerasannya tidak terlalu tinggi. Nilai ketangguhan bahan dapat dikarakterisasi melalui besarnya nilai elongasi dan kekuatan tarik dari bahan tersebut. Oleh karena itu, dengan pertimbangan tersebut maka baja merupakan pilihan yang dalam penelitian ini dianggap tepat. Jenis-jenis baja sangat banyak dan bervariatif dalam sifat dan aplikasinya.

Khusus untuk aplikasi Hammer mill ini, ada dua baja yang dapat dijadikan alternatif yaitu :

1. GS50CrMo4 (DIN)

Baja ini memiliki sifat-sifat sebagai berikut :

- Kekuatan tarik mencapai $730 \mathrm{MPa}$

- Elongasi setelah patah mencapai $11 \%$

- Kekerasan mencapai 57 HRC setelah proses perlakuan panas.

Tabel 4. Komposisi kimia GS50CrMo4 (DIN)

\begin{tabular}{|l|l|l|c|c|l|l|}
\hline$\% \mathrm{C}$ & $\% \mathrm{Si}$ & $\% \mathrm{Mn}$ & $\% \mathrm{P}$ & $\% \mathrm{~S}$ & $\% \mathrm{Cr}$ & $\% \mathrm{Mo}$ \\
\hline 0,46 & 0,25 & 0,50 & $<0,035$ & $<0,035$ & 0,90 & 0,15 \\
- & - & - & & & - & - \\
0,54 & 0,50 & 0,80 & & & 1,20 & 0,25 \\
\hline
\end{tabular}

2. ZG45Cr5Mo (Standar China)

Baja ini memiliki sifat-sifat sebagai berikut :

- Kekerasan $\geq 48$ HRC

- Harga impak $\geq 20 \mathrm{~J} / \mathrm{cm}^{2}$

Tabel 5. Komposisi kimia GS50CrMo4 (DIN)

\begin{tabular}{|l|l|c|c|c|c|c|c|}
\hline$\% \mathrm{C}$ & $\% \mathrm{Si}$ & $\% \mathrm{Mn}$ & $\% \mathrm{Cr}$ & $\% \mathrm{Mo}$ & $\% \mathrm{Cu}$ & $\% \mathrm{P}$ & $\% \mathrm{~S}$ \\
\hline $0,4-$ & $\leq 1,2$ & $1-$ & $4-6$ & 0,2 & 0,5 & 0,058 & 0,052 \\
0,6 & & 1,5 & & -1 & - & & \\
& & & & & 0,8 & & \\
\hline
\end{tabular}

Dari dua alternatif bahan tersebut, dalam penelitian ini akan dipilih bahan GS50CrMo4 karena bahan tersebut memiliki kekuatan yang tinggi juga bersifat keras. Selain itu ditinjau dari aspek komposisinya bahan ini mengandung unsur $\mathrm{Cr}$, Mo, dan Mn yang lebih rendah sehingga memiliki nilai yang lebih ekonomis dibandingkan bahan kedua.

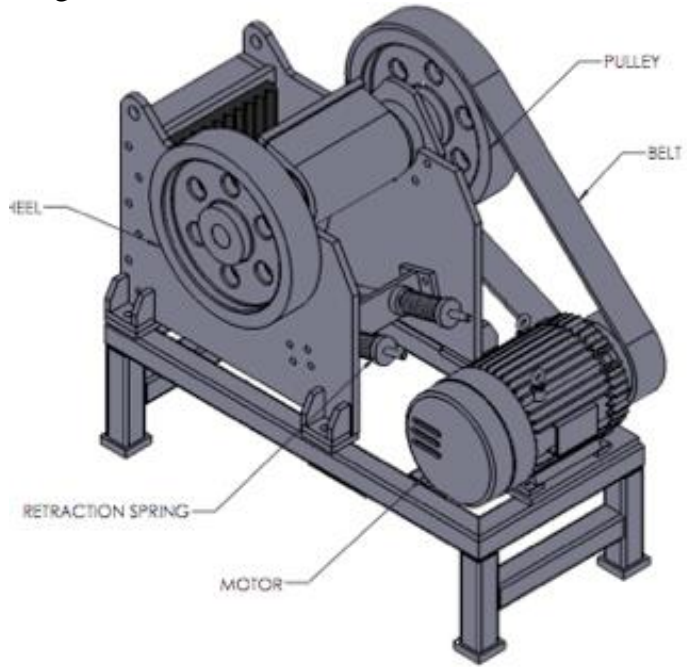

Gambar 12. Mesin jaw crusher hasil rancangan

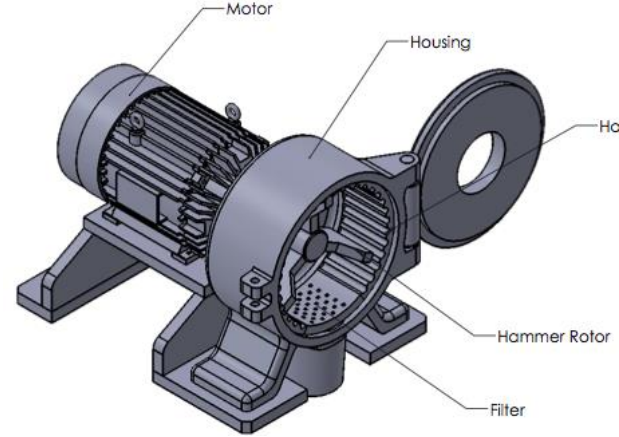

Gambar 13. Mesin hammer mill hasil rancangan

\section{PENUTUP}

\section{Kesimpulan}

Berdasarkan penelitian yang telah dilakukan diperoleh kesimpulan sebagai berikut :

1. Teknologi daur ulang pasir proses $\mathrm{CO}_{2}$ yang dihasilkan adalah dalam bentuk sistem daur ulang dan analisis/ kajian mengenai kualitas daur ulang.

2. Desain purwarupa mesin daur ulang pasir proses $\mathrm{CO}_{2}$ yang dihasilkan adalah desain mesin jaw crusher dan desain mesin hammer mill.

\section{DAFTAR PUSTAKA}

1. Daftar C. Kim Ng, P.K. Yeo \& C.M. Fam "Reclamation of Sodium Silicate Sand Moulding" Australian Journal of Basic and Applied Sciences 8)(19) Special 2014, pages 365-368

2. G. S. PATANGE, M. P. KHOND, H. J. RATHOD\& K. B. CHHADVA "Investigation of Foundry Waste Sand Reclamation Process for Small and Medium Scale Indian Foundry" International Journal of Industrial Engineering \& Technology (IJIET) ISSN 2277-4769 Vol.3, Issue 1, Mar 2013, 1-6

3. J.M. Svoboda "Foundry Sand Reclamation" Center for Materials Production 1990

4. M.V Ramana "Moulding Sand Reclamation-A Brief Review" International Journal of Latest Trends in Engineering and Technology (IJLTET) Vol. 5 Issue 1 January 2015.

5. P. Czapla, R. Dańko "The State of Art of the Mechanical Reclamation of Used Foundry Sands" ARCHIVES of FOUNDRY ENGINEERING Volume 13, Special Issue 3/2013

6. United States Department of Transportation Federal Highway Transportation, Foundry Sand Facts for Civil EngineersFirst Printing, May 2004, FHWA-IF04-004

7. Erfahrungen beim Regenerieren von GrünsandKernsandgemisch imGrünsandformverfahren, GIESSEREI-PRAXIS vol $10 / 2014$

8. http://www.junruidesign.com/product/productinfo.ph $\mathrm{p}$ ?pid $=9$

9. http://www.foundry-source.com/casting_process.htm

10. https://www.911 metallurgist.com/blog/recyclingsand-foundry-casting-mold

11. http://www.wheelabratorgroup.com/en/sites/wheelab ratorLibrary 